\title{
New approach to nanolime synthesis at ambient temperature
}

\author{
Sagrario Martínez-Ramírez ${ }^{1}$ (D) Laura R. Higueruela $^{1} \cdot$ Ignacio Cascales $^{1} \cdot$ Moisés Martín-Garrido $^{1}$. \\ María Teresa Blanco-Varela²
}

(c) Springer Nature Switzerland AG 2018

\begin{abstract}
This study explored the viability of synthesising nanolime at ambient temperature by raising calcium solubility through the formation of complexes with dissolved sugars. Micro-Raman findings confirmed the formation of nanolime particles whilst the percentage of $\mathrm{Ca}(\mathrm{OH})_{2}$ formed, observed to vary with synthesis conditions, was calculated with thermogravimetry. Nanoparticles were synthesised most productively (77\%) in a $5 \%$ sugary solution at a temperature of $25^{\circ} \mathrm{C}$ and a $4 \mathrm{~h}$ reaction time. The hexagonal nanoparticles synthesised ranged in size from 200 to $25 \mathrm{~nm}$. Portlandite formation is related to calcium complex formation with less mannitol that sucrose needed to form similar $\mathrm{NPs}$ of $\mathrm{Ca}(\mathrm{OH})_{2}$. The sugary media also favoured the formation of amorphous calcium carbonate.
\end{abstract}

Keywords Nanolime $\cdot$ Room temperature $\cdot$ Sugary solution $\cdot$ Micro-Raman · Thermogravimetry

\section{Introduction}

Products to protect and conserve historic-artistic heritage materials must be designed and developed with care, for inappropriate use may hasten deterioration. Whilst the earliest treatments were organic substances [1], in light of the issues that arose around substrate compatibility (mainly stones), today inorganic compounds are deemed more suitable and physically and chemically more substrate-compatible, although they have been less thoroughly researched [2].

One of the materials most commonly used in protection and conservation treatments is lime $\left[\mathrm{Ca}(\mathrm{OH})_{2}\right.$, also known as portlandite], primarily as a surface coating or a limestone consolidant [3-5]. Its application poses two basic problems, however: low water solubility and slow carbonation. With a water solubility of $1.7 \mathrm{~g} / \mathrm{L}$ at $20^{\circ} \mathrm{C}, \mathrm{Ca}(\mathrm{OH})_{2}$ requires large quantities of water to obtain an acceptable calcium concentration in the solution. Carbonate in turn is known to depend on $\mathrm{CO}_{2}$ concentration and relative humidity [6], both of which are difficult to control in outdoor environments. Different additives producing rapid carbonation have been studied $[7,8]$ following different strategies such as diethyl carbonation addition.

Nanolime synthesis is presently being explored to develop a treatment compound as the possible solution to those two problems. Nano- $\mathrm{Ca}(\mathrm{OH})_{2}$ can be synthesised homogeneously or heterogeneously. In the former, the hydroxide precipitates out of an aqueous solution containing a strong base $(\mathrm{NaOH})$ and a highly soluble calcium salt $\left(\mathrm{CaCl}_{2}\right.$ or $\left.\mathrm{Ca}\left(\mathrm{NO}_{3}\right)_{2}\right)$. Heterogeneous precipitation is based on $\mathrm{CaO}$ hydration in excess water. Most research has been conducted using the homogeneous procedure. In Salvadori and Dei [9] pioneered nanolime synthesis in an alcoholic medium, applying the method for synthesising nano- $\mathrm{In}(\mathrm{OH})_{3}$ described by Pérez-Maqueda [10]. They successfully synthesised $\mathrm{Ca}(\mathrm{OH})_{2}$ nanoparticles from 30 to $60 \mathrm{~nm}$ at $150^{\circ} \mathrm{C}$. Under the experimental conditions designed for synthesis, namely supersaturation, high temperature and slow mixing time, $\mathrm{Ca}(\mathrm{OH})_{2}$ nucleation was

$\square$ Sagrario Martínez-Ramírez, sagrario.martinez@csic.es; Laura R. Higueruela, Irubiohig@gmail.com; Ignacio Cascales, ignaciocascales1991@gmail.com; Moisés Martín-Garrido, mmarting16@gmail.com; María Teresa Blanco-Varela, blancomt@ietcc.csic.es | ${ }^{1}$ Instituto de Estructura de la Materia (IEM-CSIC), C/Serrano 121, 28006 Madrid, Spain. ${ }^{2}$ Instituto de Ciencias de la Construcción “Eduardo Torroja" (IETCC-CSIC), Serrano Galvache 4, 28033 Madrid, Spain.

SN Applied Sciences (2019) 1:105 | https://doi.org/10.1007/s42452-018-0122-8 
favoured over particle growth, inducing the precipitation of nano-sized calcium hydroxide particles [10-15]. The aggregated nanoparticles were subsequently dispersed (peptised) in an alcoholic medium. Although nanolime was initially regarded as inert in alcohol, Rodriguez-Navarro et al. [16], studying the effect of an alcoholic medium on $\mathrm{Ca}(\mathrm{OH})_{2}$ nanoparticle formation, observed the presence of $\mathrm{Ca}$ alkoxides able, among others, to retard the carbonation rate.

Building on those synthesis studies, in Daniele et al. [17] found that the aforementioned nanoparticles could be efficiently carbonated. Applying the homogeneous procedure and dissolving calcium chloride in Triton X-100, Daniele and Tagliere [18] synthesised hexagonal nano- $\mathrm{Ca}(\mathrm{OH})_{2}$ at $90{ }^{\circ} \mathrm{C}$, obtaining particle sizes of under $200 \mathrm{~nm}$ and reducing nanoparticle preparation time by $25 \%$. Recently the effects of natural polysaccharide on the formation of vaterite at $95^{\circ} \mathrm{C}$ has been reported [19].

To date, nanolime has been synthesised at temperatures of around $100^{\circ} \mathrm{C}[9,20,21]$ or higher [22] to decrease calcium solubility. Ambient temperature synthesis, based on the use of exchange resins, has been proposed only recently [23].

This study explores the viability of synthesising nanolime at ambient temperature by raising calcium solubility through the formation of complexes. Calcium is known to form complexes with some sugars [24], which raise its ambient temperature solubility $[25,26]$ to yield more concentrated nanoparticle solutions. Additionally, organic compounds are capable of complexing ions, when possess, at least, one pair of oxygen atoms closed to neighbouring carbons [27]. In this work both sucrose (aromatic) and mannitol (aliphatic) have been selected.
The nanolime synthesised at ambient temperature in sugary solutions in this study was characterised for structure and composition (micro-Raman and DTA) as well as size and shape (TEM). Subsequent in-depth research will address the viability of deep penetration into damaged materials, high reactivity and speedy reactions.

\section{Experimental}

\subsection{Materials}

The reagents used were Merck $99 \%$ pure calcium chloride, Panreac $98 \%$ pure sodium hydroxide, Panreac $99 \%$ pure sucrose and Panreac $99 \%$ pure mannitol.

\subsection{Nanoparticle preparation}

Solutions of $5 \%$ or $10 \%$ sucrose or mannitol were prepared in Milli-Q ultrapure, decarbonated water and used, $10 \mathrm{~mL}$ per sample, to dissolve $\mathrm{CaCl}_{2}$ to a molarity of $5 \mathrm{M}$ or $3 \mathrm{M}$. A $3 \mathrm{M} \mathrm{NaOH}$ solution prepared in $50 \mathrm{~mL}$ of the aforementioned ultrapure water was then mixed with the sugary solution in a $250 \mathrm{~mL}$ Erlenmeyer flask and constantly stirred at ambient temperature for $4 \mathrm{~h}$ or $24 \mathrm{~h}$. The variables used in nanolime synthesis are given in Table 1.

At the specified reaction time, the solutions were vacuum filtered and the solid rinsed several times with decarbonated water.

In order to determine the particle size and distribution, an image analyzer software, Digimiter, was used and 10-30 particles were analysed for each sample.

Table 1 Initial sample composition, reaction times, reaction yield and particle shape

\begin{tabular}{|c|c|c|c|c|c|c|c|c|}
\hline Sample & $\begin{array}{l}\text { Reaction } \\
\text { time (h) }\end{array}$ & $\begin{array}{l}\text { Sucrose } \\
\text { solution (\%) }\end{array}$ & $\begin{array}{l}\text { Mannitol } \\
\text { solution (\%) }\end{array}$ & {$\left[\mathrm{Ca}^{2+}\right](\mathrm{mmol})$} & {$[\mathrm{NaOH}](\mathrm{M})$} & Particle size (nm) & Particle shape & $\begin{array}{l}\mathrm{Ca}(\mathrm{OH})_{2} \\
\text { formation } \\
(\%)\end{array}$ \\
\hline S1 & 4 & 10 & & 20 & 3 & $37-142 \pm 33$ & Hexagonal & 46.0 \\
\hline $\mathrm{S} 2$ & 24 & 10 & & 20 & 3 & $12-45 \pm 15$ & Hexagonal & 69.9 \\
\hline S3 & 4 & 5 & & 20 & 3 & $6-16 \pm 5$ & Spherical & 75.2 \\
\hline S4 & 24 & 5 & & 20 & 3 & $9-32 \pm 6$ & Spherical & 60.8 \\
\hline S5 & 24 & 10 & & 10 & 3 & $8-24 \pm 5$ & Polygon & 27.5 \\
\hline S6 & 24 & 5 & & 10 & 3 & $13-36 \pm 6$ & Spherical & 68.6 \\
\hline M1 & 4 & & 10 & 20 & 3 & $7-22 \pm 5$ & Polygon & 62.9 \\
\hline M2 & 24 & & 10 & 20 & 3 & $20-70 \pm 10$ & Hexagonal & 65.8 \\
\hline M3 & 4 & & 5 & 20 & 3 & $21-60 \pm 12$ & Spherical & 76.5 \\
\hline M4 & 24 & & 5 & 20 & 3 & $95-182 \pm 37$ & Polygon & 48.9 \\
\hline M5 & 24 & & 10 & 10 & 3 & $21-45 \pm 5$ & Hexagonal & 63.3 \\
\hline M6 & 24 & & 5 & 10 & 3 & $55-97 \pm 17$ & Hexagonal & 60.0 \\
\hline
\end{tabular}

Bold and italics indicates samples with lower particle size; bold indicates samples with higher reaction yield 


\subsection{Characterisation techniques}

The crystal phases of the synthesised samples was determined by analysing the nanoparticles under a Renishaw InVia micro-Raman spectrometer fitted with a Leica microscope and laser diode (785 nm)- and Renishaw YAG:Nd $(532 \mathrm{~nm})$ laser-based excitation. The measuring conditions were: laser output power, $25 \mathrm{~mW}$ for the $785 \mathrm{~nm}$ laser and $5 \mathrm{~mW}$ for the $532 \mathrm{~nm}$ laser; acquisition time, $10 \mathrm{~s}$; one accumulation; microscope magnification, 50x. Laser frequency and intensity were calibrated with a silicon standard prior to use.

One drop of each sample liquid was ultrasound-dispersed in $10 \%$ ethanol and deposited on a carbon-coated copper grid for study under a Hitachi-8000 transmission electron microscope to determine nanoparticle size and shape.

The yield for each synthesis procedure, defined as the amount of $\mathrm{Ca}(\mathrm{OH})_{2}$ formed in the samples, was determined on a PerkinElmer thermogravimetric analyser (DTA), heating the samples in a nitrogen atmosphere from 25 to $950^{\circ} \mathrm{C}$ at a rate of $10^{\circ} \mathrm{C} / \mathrm{min}$.

\section{Results and discussion}

Nano- $\mathrm{Ca}(\mathrm{OH})_{2}$ was synthesised under the 12 sets of conditions described in Table 1, six in sucrose and six in mannitol.

All the micro-Raman spectra reproduced in Fig. 1 for the samples synthesised in sucrose exhibited signals characteristic of portlandite: a narrow, high intensity band at $3618 \mathrm{~cm}^{-1}$ attributed to $\mathrm{O}-\mathrm{H}$ bond stretching vibrations and a medium intensity, medium width band at $358 \mathrm{~cm}^{-1}$, associated with $\mathrm{Ca}-\mathrm{O}$ bond lattice vibrations [28]. All the samples also contained a wide, medium intensity signal in the $1100 \mathrm{~cm}^{-1}$ to $1050 \mathrm{~cm}^{-1}$ range, generated by carbonate group vibrations. Enlarging the $1200 \mathrm{~cm}^{-1}$ to $900 \mathrm{~cm}^{-1}$ range revealed a band in some samples at $1085 \mathrm{~cm}^{-1}$ or $1070 \mathrm{~cm}^{-1}$. Both could be attributed to carbonate $\left(v_{1}\right)$ group symmetric stretching vibrations, the first generated by calcite [29] and the second by amorphous carbonates (ACC) [30].

The spectra for the mannitol solutions (Fig. 1) were similar under all synthesis conditions, with portlandite generating the most intense signals. As in sucrose, signals indicative of both crystalline (calcite) and amorphous calcium carbonate formation were observed, with the latter prevailing over calcite. The carbonate signals were more intense here than when the nanoparticles were synthesised in a sucrose solution. Under both sugary solutions sucrose and mannitol, portlandite is formed, as well as calcium carbonate. In order to quantify the amount of different compounds formed, thermogravimetric analysis was performed in all the samples.

The thermogravimetric curves reproduced in Fig. 2 for the nanolime-containing solutions showed similar weight loss patterns in all 12 samples. Four distinct weight loss zones could be identified on the thermograms: $25^{\circ} \mathrm{C}$ to $120^{\circ} \mathrm{C}$ (elimination of moisture); $120^{\circ} \mathrm{C}$ to $330^{\circ} \mathrm{C}$ (amorphous calcium carbonate dehydration [31]); $345^{\circ} \mathrm{C}$ to $420^{\circ} \mathrm{C}$ (calcium hydroxide dehydroxylation); and $430^{\circ} \mathrm{C}$ to $800^{\circ} \mathrm{C}$ (calcium carbonate decarbonation).

Table 2 gives the DTA-determined mass loss in the various temperature ranges, indicative of the percentage of amorphous carbonates, lime and crystalline calcium carbonate present in the sample solutions as per the equations shown below.
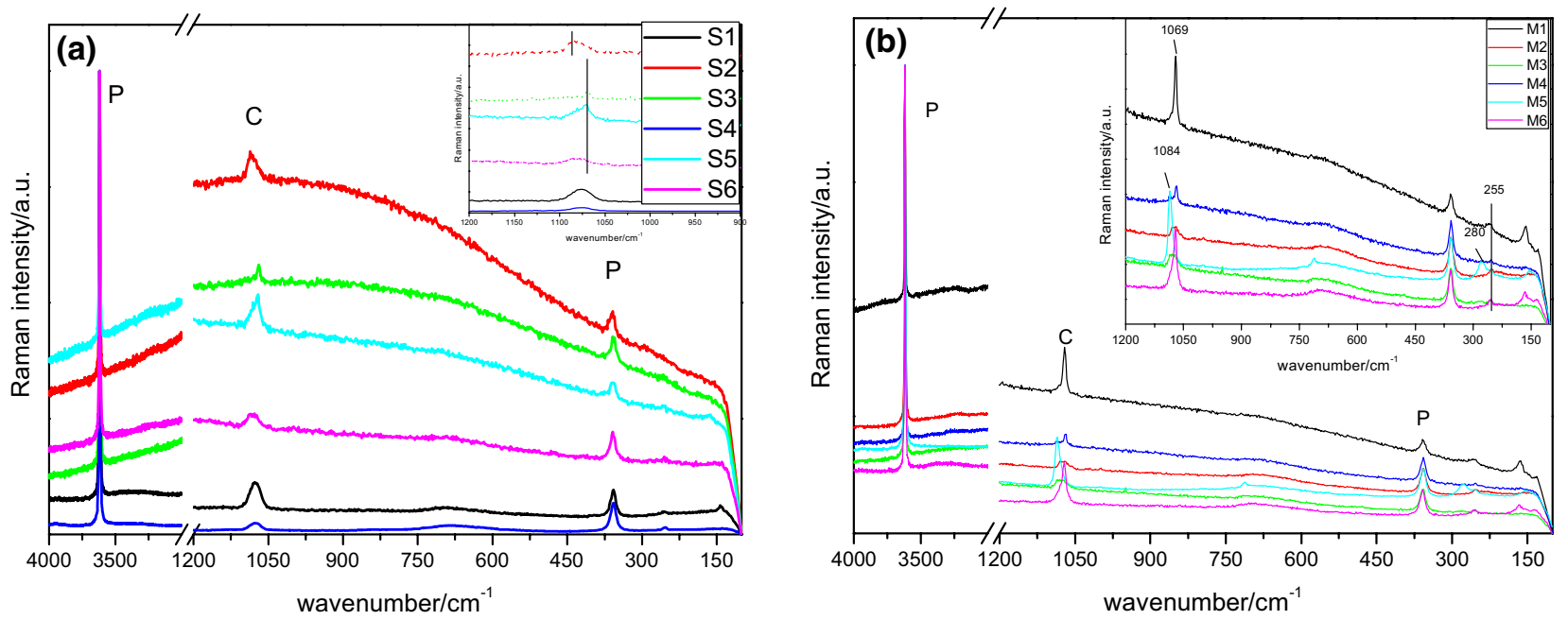

Fig. 1 Raman spectra for the nanoparticles synthesised in a sucrose and $\mathbf{b}$ mannitol (laser $\lambda=532 \mathrm{~nm}) . \mathrm{P}=\mathrm{Ca}(\mathrm{OH})_{2} ; \mathrm{C}=\mathrm{CaCO}{ }_{3}$ 

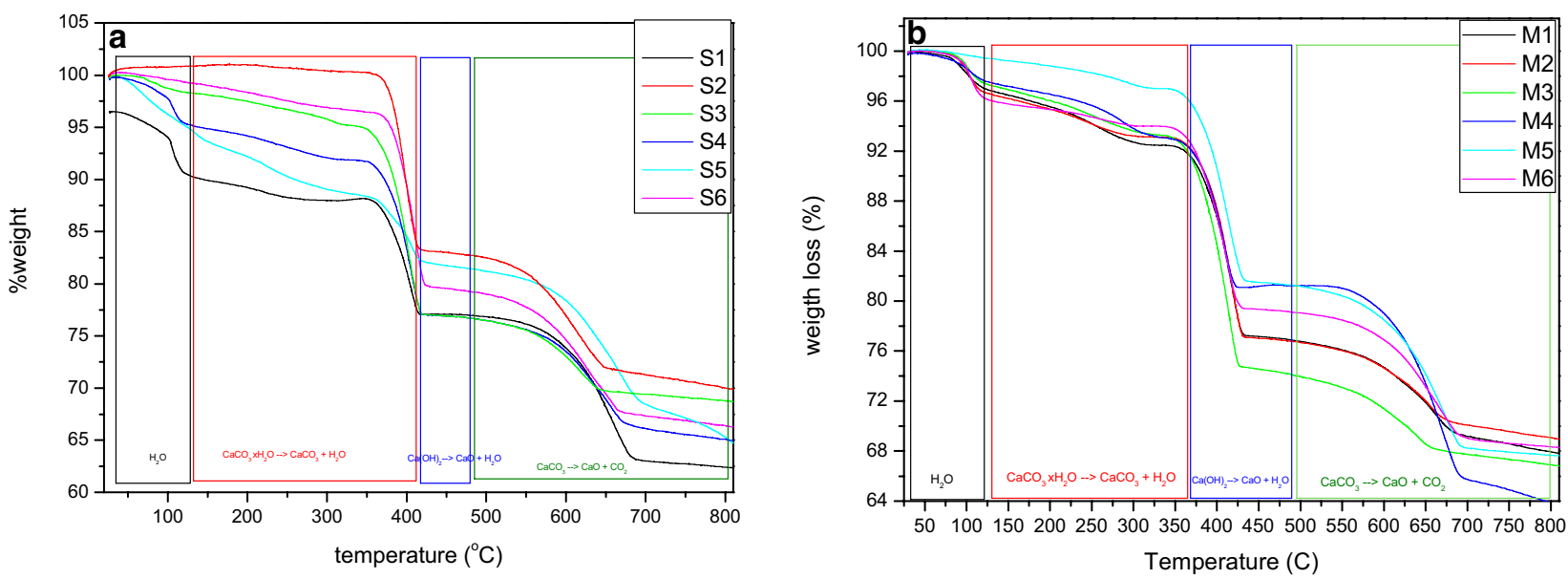

Fig. 2 Thermogravimetric curves for nanolime-containing a sucrose and $\mathbf{b}$ mannitol solutions

Table 2 DTA-determined percentages of $\mathrm{ACC}, \mathrm{Ca}(\mathrm{OH})_{2}$ and $\mathrm{CaCO}_{3}$

\begin{tabular}{|c|c|c|c|c|c|c|}
\hline$\%$ of mass $\left(\mathrm{T}\right.$ in $\left.{ }^{\circ} \mathrm{C}\right)$ & S1 & S2 & S3 & S4 & S5 & S6 \\
\hline$\% \mathrm{H}_{2} \mathrm{O}\left(25-120^{\circ} \mathrm{C}\right)$ & 5.9 & 0 & 1.7 & 4.3 & 5 & 0.7 \\
\hline$\% \operatorname{ACC}\left(120-330^{\circ} \mathrm{C}\right)$ & 11.3 & 0 & 15.1 & 16.9 & 29.6 & 13.2 \\
\hline$\% \mathrm{Ca}(\mathrm{OH})_{2}\left(345-420^{\circ} \mathrm{C}\right)$ & 46.04 & 69.89 & 75.23 & 60.84 & 27.54 & 68.65 \\
\hline \multirow[t]{2}{*}{$\% \mathrm{CaCO}_{3}^{\mathrm{a}}\left(430-800^{\circ} \mathrm{C}\right)$} & 22.3 & 30.0 & 3.6 & 10.3 & 21.8 & 16.8 \\
\hline & M1 & M2 & M3 & M4 & M5 & M6 \\
\hline$\% \mathrm{H}_{2} \mathrm{O}\left(25-120^{\circ} \mathrm{C}\right)$ & 3.1 & 3.3 & 2.7 & 2.4 & 0.5 & 3.9 \\
\hline$\% \operatorname{ACC}\left(120-330^{\circ} \mathrm{C}\right)$ & 20.7 & 17.4 & 19.3 & 21.2 & 11.7 & 9.9 \\
\hline$\% \mathrm{Ca}(\mathrm{OH})_{2}\left(345-420^{\circ} \mathrm{C}\right)$ & 62.9 & 65.8 & 76.5 & 48.9 & 63.3 & 60.0 \\
\hline$\% \mathrm{CaCO}_{3}^{\mathrm{a}}\left(430-800^{\circ} \mathrm{C}\right)$ & 0.44 & 1.0 & 1.4 & 18.4 & 20.1 & 15.3 \\
\hline
\end{tabular}

${ }^{a}$ Crystalline calcium carbonate

$$
\begin{aligned}
& \mathrm{CaCO}_{3} \cdot 1.5 \mathrm{H}_{2} \mathrm{O} \rightarrow \mathrm{CaCO}_{3}+1.5 \mathrm{H}_{2} \mathrm{O} \\
& \mathrm{Ca}(\mathrm{OH})_{2} \rightarrow \mathrm{CaO}+\mathrm{H}_{2} \mathrm{O} \\
& \mathrm{CaCO}_{3} \rightarrow \mathrm{CaO}+\mathrm{CO}_{2}
\end{aligned}
$$

Further to the weight loss data in the $345^{\circ} \mathrm{C}$ to $420^{\circ} \mathrm{C}$ range (Table 2), lime formation were greater than $50 \%$ except in all synthesis solutions except $\mathrm{S} 1 \mathrm{t}=4 \mathrm{~h}, 10 \%$ sucrose), S5 ( $\mathrm{t}=24 \mathrm{~h}, 10 \%$ sucrose) and M4 ( $\mathrm{t}=24 \mathrm{~h}, 5 \%$ mannitol). The data also showed that the highest amount of calcium hydroxide in both cases was obtained when synthesis was conducted for $4 \mathrm{~h}$ at $5 \%$ sugar with the highest calcium concentration ( $\mathrm{S} 3$ and M3). According to those findings, a $5 \%$ concentration of sucrose dissolved sufficient calcium to synthesise nanolime. Amorphous calcium carbonate was formed in all cases as well as crystalline carbonate.

Representing the amount of $\mathrm{Ca}$ that forms portlandite versus initial amount of $\mathrm{Ca}$ per mol of sucrose or

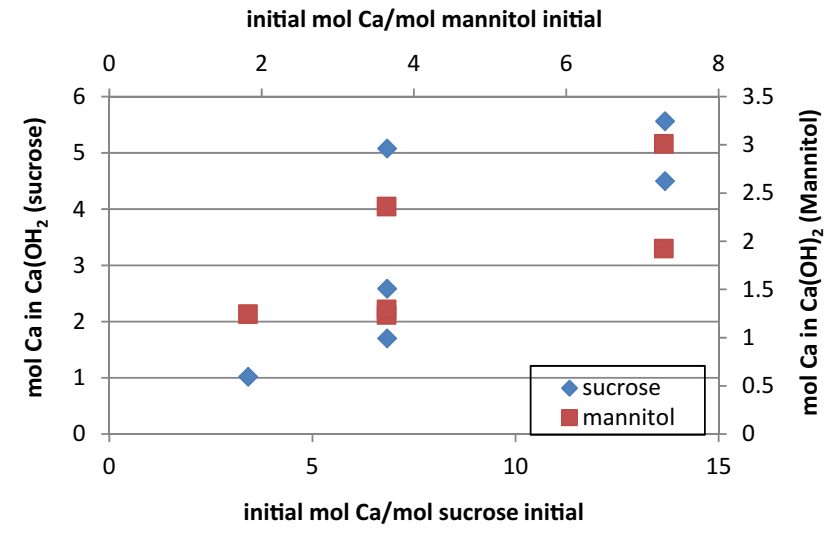

Fig. 3 Initial $\mathrm{mol} \mathrm{Ca} / \mathrm{mol}$ sugary solution versus $\mathrm{mol} \mathrm{Ca}$ in portlandite 
mannitol (Fig. 3) is observed that more $\mathrm{Ca}(\mathrm{OH})_{2}$ is formed as the initial $\mathrm{mol} \mathrm{Ca} / \mathrm{mol}$ sugary solution increases, then portlandite formation is related to calcium complex formation. According to Pannetier [24] a calcium-sucrose complex is formed with different calcium molecules, depending on the calcium/sucrose ratio. Assuming calcium-sugary solution complex formation from Pannetier results, and trying to understand the effect of sucrose or mannitol in calcium complexation, the ratio of the mol of calcium that forms portlandite against the mol of sugary solutions was calculated. Then Table 3 shows the amount of calcium that forms a complex with the sucrose or mannitol to form the nanoparticles of $\mathrm{Ca}(\mathrm{OH})_{2}$ showing that mannitol needs less moles of calcium to form NPs of $\mathrm{Ca}(\mathrm{OH})_{2}$. Six-calcium coordination promotes sucrose polymerization [21] and further the complexes formed involves between 1 and $5 \mathrm{~mol}$ of calcium per sucrose mol. For the manitol, as a monomeric molecule, calcium complexation is lower than for sucrose with 1.2-3 mol of calcium per mannitol mol. At this point computer simulations and modelling approaches will be required to improve our understanding of the influence of sugary solutions on the nanolime formation.

According to the DTA curves reproduced in Fig. 4, sample M5 had no peak in the range $\left(25^{\circ} \mathrm{C}\right.$ to $\left.120^{\circ} \mathrm{C}\right)$ associated with adsorbed water loss. The exothermal peak attributed to ACC conversion to crystalline calcium carbonate [30] was not visible on this curve either, for at around $340{ }^{\circ} \mathrm{C}$ it overlapped with the peak denoting exothermal calcium hydroxide dehydroxylation. The absence of peaks at $186^{\circ} \mathrm{C}$ and $166^{\circ} \mathrm{C}$, the melting points of sucrose and mannitol, respectively, was an indication that neither sugar was present in the solid samples.

Table $3 \mathrm{Mol}$ Ca that forms nanoparticles of $\mathrm{Ca}(\mathrm{OH})_{2}$ versus mol of sucrose or mannitol

\begin{tabular}{ll}
\hline Sample & Mol Ca in $\mathrm{CH} / \mathrm{mol}$ sucrose \\
\hline S1 & 1.70 \\
S2 & 2.58 \\
S3 & 5.56 \\
S4 & 4.50 \\
S5 & 1.02 \\
S6 & 5.08 \\
\hline Sample & Mol Ca in CH/mol mannitol \\
\hline M1 & 1.24 \\
M2 & 1.29 \\
M3 & 3.01 \\
M4 & 1.92 \\
M5 & 1.25 \\
M6 & 2.36 \\
\hline
\end{tabular}

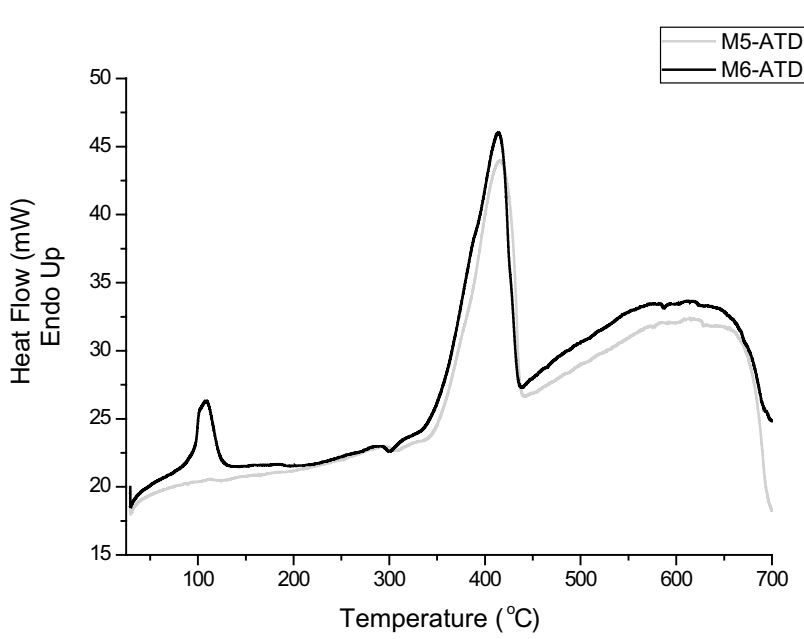

Fig. 4 DTA curves for samples M5 and M6 in the $25^{\circ} \mathrm{C}$ to $700{ }^{\circ} \mathrm{C}$ range

It is also interesting to remark that ACC, which is less stable than calcite, formed during nanolime synthesis thanks to the stabilisation of this amorphous compound in the presence of organic compounds [32] (sucrose and mannitol in this study).

Nanolime particle size and shape, determined with TEM techniques, are given in Table 1 and Fig. 5. Where mannitol was the solvent, the particles were consistently hexagonal, with size varying from 10 to $50 \mathrm{~nm}$, except in solution M4 ( $24 \mathrm{~h}, 5 \%$ mannitol) which produced very large particles, at around $200 \mathrm{~nm}$. In the sucrose solutions, particle size was also generally small (approximately $5 \mathrm{~nm}$ to $50 \mathrm{~nm}$ ), except where synthesis was conducted at $10 \%$ for $4 \mathrm{~h}(\mathrm{~S} 1)$, when size ranged from 40 to $150 \mathrm{~nm}$. The solutions yielding the smallest nano- $\mathrm{Ca}(\mathrm{OH})_{2}$ particles had a $5 \%$ sucrose concentration, $20 \mathrm{mmol}$ of $\mathrm{CaCl}_{2}$ and a reaction time of $4 \mathrm{~h}(\mathrm{~S} 3)$, then it is not necessary a high sucrose solution. However, for mannitol solution, higher concentration is needed for lower particle size.

Particle morphology varied when sucrose was the solvent, whereas mannitol generated consistently hexagonal particles. Significantly, despite the differences in effectiveness of the synthetic procedures used, the nanolime obtained always exhibited more or less regular shapes.

With a $24 \mathrm{~h}$ reaction time and $10 \%$ sugar concentration, reducing the calcium content from $20 \mathrm{mmol}$ (S2/ $\mathrm{M} 2$ ) to $10 \mathrm{mmol}$ (S5/M5) lowered nanoparticle formation, much more notably in sucrose (from 70 to $27 \%$ ) than in mannitol (from 66 to $63 \%$ ). As sucrose and calcium can combine into an adduct $[24,33]$ and the $10 \%$ medium (S2 and S5) contained more sugar (than the 5\% medium) able to form Ca complexes, less of the element was free to generate nanolime. At a lower calcium concentration, the percentage of nanoparticles consequently declined 


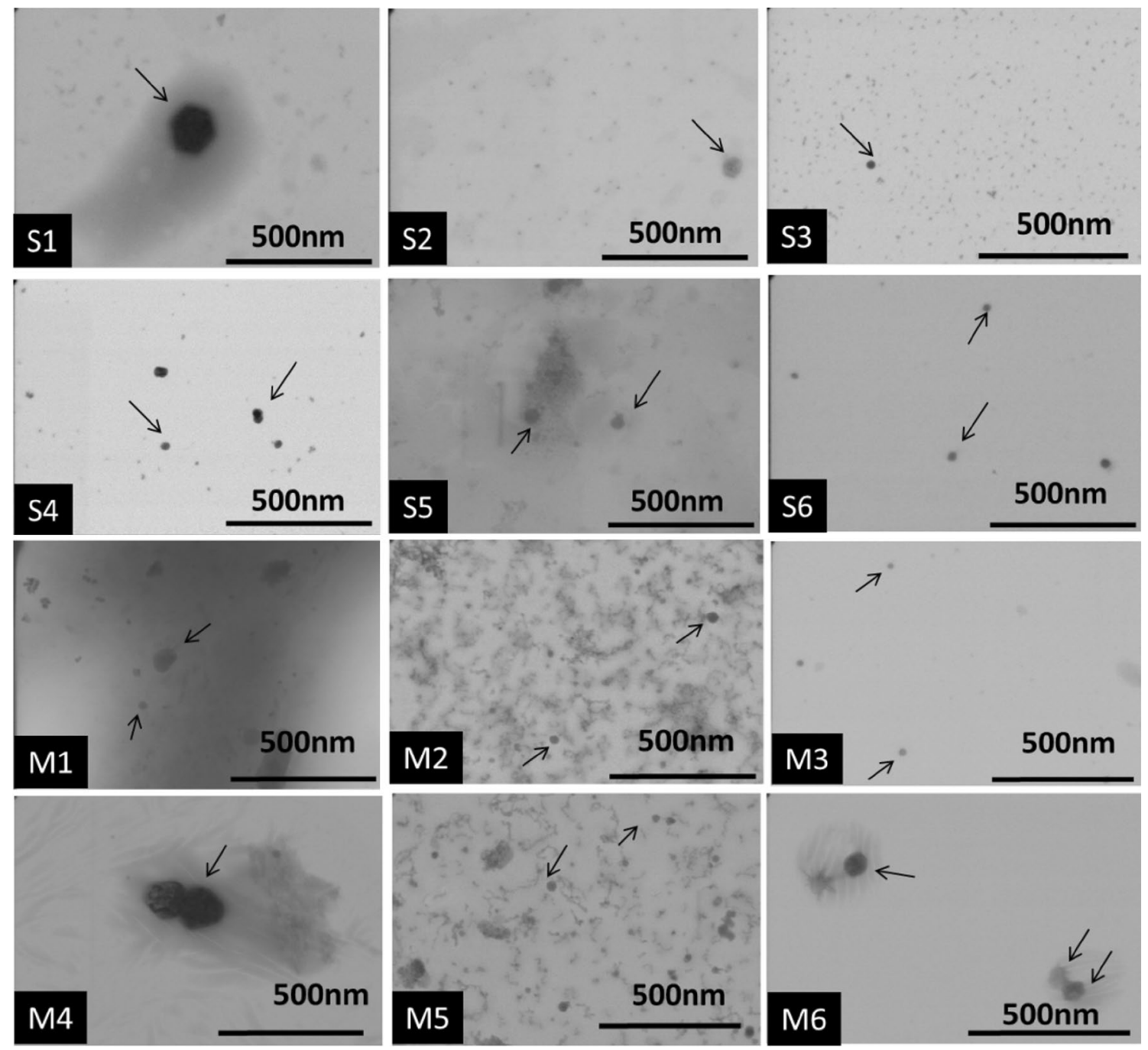

Fig. 5 TEM micrographs of the 12 samples synthesised

(from $70 \%$ in $\mathrm{S} 2$ to $27 \%$ in S5). In $5 \%$ solutions, in contrast, lowering the calcium concentration had the opposite effect, slightly raising the nanolime yield (from $24 \%$ in S3 to $28 \%$ in S6). Calcium adduct formation at different concentrations of the two solutions would be a line of research worth pursuing.

Whilst the type of sugar appeared to have no obvious impact on particle size, it did impact calcium hydroxide formation, for mannitol generated a higher percentage of nanolime ( $49 \%$ to $76 \%$ ) than sucrose ( $27 \%$ to $75 \%$ ).

\section{Conclusions}

Calcium hydroxide nanoparticles were obtained at ambient temperature using sucrose and mannitol in $10 \%$ and $5 \%$ solution.
Both micro-Raman and DTA studies confirmed nanolime formation at portlandite formation ranging from 27 to $77 \%$, depending on the experimental conditions. Yield was highest at: $\mathrm{T}=25^{\circ} \mathrm{C}$; reaction time $=4 \mathrm{~h}$; solvent (sucrose or mannitol) concentration $=5 \%$; calcium content $=20 \mathrm{mmol}$; and $\mathrm{NaOH}$ molarity $=3 \mathrm{M}$.

The smallest nanoparticles were obtained under the following conditions: $\mathrm{T}=25^{\circ} \mathrm{C}$; reaction time $=4 \mathrm{~h}$; solvent (sucrose or mannitol) concentration $=5$ or $10 \%$ respectively; calcium content $=10 \mathrm{mmol}$; and $\mathrm{NaOH}$ molarity $=3 \mathrm{M}$. The findings confirmed the viability of synthesising nano- $\mathrm{Ca}(\mathrm{OH})_{2}$ at ambient temperature.

In mannitol the nanoparticles were consistently hexagonal, whereas in sucrose shape varied (hexagonal, spherical, polygon) depending on experimental conditions. Synthesis conducted in a $5 \%$ mannitol solution containing $20 \mathrm{mmol}$ of calcium for $24 \mathrm{~h}$ yielded very large $(200 \mathrm{~nm})$ particles. 
Portlandite formation is related to calcium complex formation with less mannitol that sucrose needed to form similar NPs of $\mathrm{Ca}(\mathrm{OH})_{2}$. Furthermore modelling studies will be required.

The sugar content favoured amorphous calcium carbonate formation.

Acknowledgements This research was supported by the Comunidad de Madrid and European Social Fund (Program GEOMATERIAL-S2013/ MIT-2914).

\section{Compliance with ethical standards}

Conflict of interest The authors declare that they have no conflict of interest.

\section{References}

1. Inigo AC, Supit JFD, Prieto O, Rives V (2007) Change in microporosity of granitic building stones upon consolidation treatments. J Mater Civil Eng 19:437-440. https://doi.org/10.1061/ (ASCE)0899-1561(2007)19:5(437)

2. Hansen E, Doehne E, Fidler J, Larson J, Martin B, Matteini M, Rodriguez-Navarro C, Pardo ES, Price C, de Tagle A, Teutonico JM, Weiss N (2003) A review of selected inorganic consolidants and protective treatments for porous calcareous materials. Stud Conserv 48:13-25. https://doi.org/10.1179/sic.2003.48.Suppl ement-1.13

3. D'Armada P, Hirst E (2012) Nano-lime for consolidation of plaster and stone. J Archit Conserv 18:63-80. https://doi. org/10.1080/13556207.2012.10785104

4. Chelazzi D, Poggi G, Jaidar Y, Toccafondi N, Giorgi R, Baglioni P (2013) Hydroxide nanoparticles for cultural heritage: consolidation and protection of wall paintings and carbonate materials. J Colloid Interface Sci 392:42-49. https://doi.org/10.1016/j. jcis.2012.09.069

5. López-Arce P, Gómez-Villalba LS, Martínez-Ramírez S, Álvarez De Buergo M, Fort R (2011) Influence of relative humidity on the carbonation of calcium hydroxide nanoparticles and the formation of calcium carbonate polymorphs. Powder Technol 205:263-269. https://doi.org/10.1016/j.powtec.2010.09.026

6. Van Balen K (2005) Carbonation reaction of lime, kinetics at ambient temperature. Cem Concr Res 35:647-657. https://doi. org/10.1016/j.cemconres.2004.06.020

7. Xiang $L$, Xiang $Y$, Wang ZG, Jin $Y(2002)$ Influence of chemical additives on the formation of super-fine calcium carbonate. Powder Technol 126:129-133. https://doi.org/10.1016/S0032 -5910(02)00047-5

8. Ergenc D, Fort R, Santos Silva A, Veiga R, Sanz-Arauz D (2018) The effects of DiloCarB as carbonation accelerator on the properties of lime mortars. Mater Struct 51:10-26. https://doi.org/10.1617/ s11527-018-1140-0

9. Salvadori $B$, Dei $L$ (2001) Synthesis of $\mathrm{Ca}(\mathrm{OH})_{2}$ nanoparticles from diols. Langmuir 17:2371-2374. https://doi.org/10.1021/ la0015967

10. Pérez Maqueda LA, Wang L, Matijevic E (1998) Nanosize indium hidroxide by peptization of colloidal precipitates. Langmuir 14:4397-4401. https://doi.org/10.1021/la980149c
11. Yura K, Fredrikson KC, Matijevic E (1990) Preparation and properties of uniform colloidal indium compounds of different morphologies. Colloid Surf 50:281-293

12. Wilhelmy DM, Matlte E (1984) Preparation and properties of monodispersed spherical particles of zinc sulphide. J Chem Soc 80:563-570

13. Matijevic E, Scheiner P (1978) Ferric hydrous oxide sols: III. Preparation of uniform particles hydrolysis of $\mathrm{Fe}$ (III)-chloride,-nitrate, and -perchlorate solutions. J Colloid Interface Sci 63:509-524

14. Hamada S, Kudo Y, Minagawa K (1990) The formation of monodispersed Indium(III) hydroxide par by force hydrolysis at elevated temperature. Bull Chem Soc Jpn 63:102-107

15. Sugimoto T, Matijevic E (1980) Formation of uniform spherical magnetite particles by cristallization from ferrous hydroxide gels. J Colloid Interface Sci 74:227-243

16. Rodriguez-Navarro C, Vettori I, Ruiz-Agudo E (2016) Kinetics and mechanism of calcium hydroxide conversion into calcium alkoxides: implications in heritage conservation using nanolimes. Langmuir 32:5183-5194. https://doi.org/10.1021/acs.langm uir.6b01065

17. Daniele V, Taglieri G, Quaresima R (2008) The nanolimes in cultural heritage conservation: characterisation and analysis of the carbonatation process. J Cult Herit 9:294-301. https://doi. org/10.1016/j.culher.2007.10.007

18. Daniele $V$, Taglieri $G$ (2012) Synthesis of $\mathrm{Ca}(\mathrm{OH})_{2}$ nanoparticles with the addition of Triton X-100. Protective treatments on natural stones: preliminary results. J Cult Herit 13:40-46. https://doi. org/10.1016/j.culher.2011.05.007

19. Saraya ME-SI, Rokbaa HHAE-L (2017) Formation and stabilization of vaterite calcium carbonate by using natural polysaccharide. Adv Nanoparticles 6:158-182. https://doi.org/10.4236/ anp.2017.64014

20. Taglieri G, Mondelli C, Daniele V, Pusceddu E, Scoccia G (2014) Synthesis, textural and structural properties of calcium hydroxide nanoparticles in hydro-alcoholic suspension. Adv Mater Phys Chem 4:50-59. https://doi.org/10.4236/ampc.2014.43008

21. Borsoi G, Lubelli $B$, van Hees $R$, Veiga $R$, Santos Silva A, Colla L, Fedelee L, Tomasin P (2016) Effect of solvent on nanolime transport within limestone: how to improve in-depth deposition. Colloids Surf A Physicochem Eng Asp 497:171-181. https ://doi.org/10.1016/j.colsurfa.2016.03.007

22. Ambrosi M, Dei L, Giorgi R, Neto Ch, Baglioni P (2001) Colloidal particles of $\mathrm{Ca}(\mathrm{OH})_{2}$ : properties and applications to restoration of frescoes. Langmuir 17:4251-4255. https://doi.org/10.1021/ la010269b

23. Taglieri G, Daniele V, Del Re G, Volpe R (2015) A new and original method to produce $\mathrm{Ca}(\mathrm{OH})_{2}$ nanoparticles by using an anion exchange resin. Adv Nanoparticles 4:17-24. https://doi. org/10.1021/la010269b

24. Pannetier N, Khoukh A, François J (2001) Physico-chemical study of sucrose and calcium ions interactions in alkaline aqueous solutions. Macromol Symp 166:203-208

25. Carlson ET, Berman HA (1960) Some observations of the calcium aluminate carbonate hydrates. J Res Natl Bur Stand 64:333-341

26. Aguilera J, Blanco-Varela MT, Vazquez T (2001) Procedure of synthesis of thaumasite. Cem Concr Res 31:1163-1168. https://doi. org/10.1016/S0008-8846(01)00536-1

27. Kinrade SD, Del Nin JW, Schach AS, Sloan TA, Wilson KL, Knight CTG (1999) Stable five- and six-coordinated silicate anions in aqueous solution. Science 285:1542-1545

28. Garbevw K, Stemmermann P, Black L, Breen C, Yarwood J, Gasharova B (2007) Structural features of C-S-H(I) and its carbonation in air-a Raman spectroscopic study. Part I: fresh phases. J Am Ceram Soc 90:900-907. https://doi.org/10.111 1/j.1551-2916.2006.01428.x 
29. Martinez-Ramirez S, Domingo C, Fortes C, Blanco-Varela MT (2003) Micro-Raman spectroscopy applied to depth profiles of carbontes formed in lime mortar. Cem Concr Res 33:2063-2068. https://doi.org/10.1016/S0008-8846(03)00227-8

30. Wehrmeister $U$, Jacob DE, Soldati AL, Loges $N$, Hager $T$, Hofmeister W (2011) Amorphous, nanocrystalline and cristalline calcium carbonates in biologial materials. J Raman Spectr 42:926-935. https://doi.org/10.1002/jrs.2835

31. Rodriguez-Navarro C, Elerta K, Ševčík R (2016) Amorphous and crystalline calcium carbonate phases during carbonation of nanolimes: implications in heritage conservation. Cryst Eng Commun 18:6594-6607. https://doi.org/10.1039/c6ce01202g

32. Konrad F, Gallien F, Gerard DE, Dietzel M (2016) Transformation of amorphous calcium carbonate in air. Cryst Growth Des 16:6310-6317. https://doi.org/10.1021/acs.cgd.6b00906

33. Pannetier N, Habas JP, Peyrelasse J, Francëois J (1999) Rheological properties of the system lime/sucrose/water. Rheol Acta $38: 241-250$ 